\title{
CAFFEINE STRONGLY IMPROVES MOTILITY PARAMETERS OF TURKEY SPERMATOZOA WITH NO EFFECT ON CELL VIABILITY
}

\author{
Tomáš SlaninA $^{1 *}$, Michal MišKeJE ${ }^{2}$, Filip TiRPÁK ${ }^{1}$, Martyna BŁASZCZYK ${ }^{3}$, \\ Grzegorz FORMICKI ${ }^{3}$ and Peter MASSÁNYI ${ }^{1,3}$ \\ ${ }^{1}$ Department of Animal Physiology, Faculty of Biotechnology and Food Sciences, \\ Slovak University of Agriculture in Nitra, Tr. A. Hlinku 2, 94976 Nitra, Slovakia; \\ ${ }^{2}$ AgroBioTech Research Centre, Slovak University of Agriculture in Nitra, Nitra, \\ Slovakia; ${ }^{3}$ Institute of Biology, Pedagogical University of Kraków, Kraków, Poland
}

(Received 1 August 2017; accepted 6 November 2017)

\begin{abstract}
The purpose of this study was to evaluate the impact of caffeine on turkey spermatozoa during in vitro incubation. Experimental samples were prepared by diluting the raw semen with nine different concentrations of caffeine - from $0.078125 \mathrm{mg} / \mathrm{mL}$ to $10 \mathrm{mg} / \mathrm{mL}$. The individual motility parameters were evaluated by the Computer Assisted Semen Analyser (CASA) system, and the viability of spermatozoa was evaluated using eosin-nigrosin staining. Selected parameters were recorded at six time periods: $0,1,2,3,4$ and $5 \mathrm{~h}$ at $5{ }^{\circ} \mathrm{C}$ and $41^{\circ} \mathrm{C}$. A significantly higher motility and progressive motility of spermatozoa ( $\mathrm{P}<0.01$ and $\mathrm{P}<0.001$, respectively) was detected in the samples containing caffeine ranging from 0.15625 to $7.5 \mathrm{mg} / \mathrm{mL}$ as compared to the control sample at $5{ }^{\circ} \mathrm{C}$. At an incubation temperature of $41^{\circ} \mathrm{C}$ the positive effect of caffeine on motility parameters was observed only at the beginning of incubation (at times 0 and 1). The tested caffeine concentrations showed no significant effect on the viability of turkey spermatozoa at any time period of incubation. A higher percentage of dead spermatozoa was observed for incubation at $41{ }^{\circ} \mathrm{C}$ (from $5.96 \%$ to $11.1 \%$ ) in comparison to $5{ }^{\circ} \mathrm{C}$ (from $1.62 \%$ to $5.79 \%$ ). The results suggest that caffeine can be used as a suitable component of turkey semen extenders and has the potential to improve fertility.
\end{abstract} caffeine

Key words: Turkey, sperm storage, spermatozoa, motility, viability,

One of the most important issues in poultry breeding is the identification of males with high fertilising ability. Besides genetic conditioning, there are many factors that affect this ability. These include age, season, amount of light, state of health and nutrition, number of copulations or ejaculations per day, and spermatozoa competition (Paluch et al., 2013). In vitro liquid storage of turkey

*Corresponding author; E-mail address: tomas.slanina@uniag.sk;

Phone: 0037-641-4288; Fax: 0037-641-4899 
semen is very important in the management of male turkeys, because artificial insemination is the only possible way to ensure and maintain the large-scale production of turkeys (Slanina et al., 2015b).

Freshly ejaculated mammalian spermatozoa are not capable of immediately fertilising the oocyte until their capacitation is completed. Capacitation can occur either in the female reproductive tract or in a corresponding medium under in vitro conditions (Mao et al., 2005). The additive solutions most frequently used for improving the motility of human spermatozoa are derivates of pentoxifylline and methylxanthine which inhibit phosphodiesterase and raise the cellular level of cyclic adenosine monophosphate (cAMP). The increased level of cAMP results in heightened glycolysis which generates adenosine triphosphate (ATP) used as energy for the movement of spermatozoa (Taylor et al., 2013). Several studies reporting pentoxifylline-improved motility of fresh and frozen-thawed semen have been published (Yovich et al., 1990; Paul et al., 1995). Another phosphodiesterase-inhibiting methylxanthine which was examined for its beneficial effects on the enhancement of motility parameters is caffeine (Carrell and Peterson, 2010). However, the study of Henkel and Schill (2003) implied that caffeine may have a negative influence on plasma membrane structure and fertilising ability. Caffeine can also affect cell metabolism, which activity is dependent on the concentration of calcium ions. Furthermore, in vitro fertilisation in cattle can be improved by the use of heparin due to its synergistic action with caffeine (Barakat et al., 2015).

High concentrations of caffeine (1,3,7-trimethylxanthine) inhibit cAMPphosphodiesterase activity. This inhibition leads to elevated levels of intracellular adenylyl cyclase/cyclic adenosine 3', 5'-monophosphate (cAMP) which acts as a second messenger that increases sperm motility and stimulates sperm capacitation in humans (Nassar et al., 1999), bulls (Coscioni et al., 2001) and boars (Funahashi and Nagai, 2001). Therefore, via the capacitation process caffeine eases the penetration of spermatozoa through the uterine cervix (Funahashi and Nagai, 2001). At the same time, different effects of caffeine on the morphology of human spermatozoa have been reported. Harrison et al. (1980) demonstrated ultrastructural abnormalities caused by caffeine, whereas Barkay et al. (1984) reported that caffeine did not induce any damage in human spermatozoa. Funahashi and Nagai (2001) noted that, in addition to the stimulation of capacitation, caffeine induces spontaneous acrosome reaction in boar spermatozoa. In almost all methods of in vitro fertilisation of pig ova with fresh or frozen semen containing caffeine, an abnormally high occurrence of polysperm penetration was recorded (Funahashi and Nagai, 2001).

Caffeine possibly has beneficial effects also on sow fertility. Reduction of the activity of polymorphonuclear leukocytes increases the number of spermatozoa reaching the place of fecundation in vivo, as a consequence of which the fertility rate is elevated (Yamaguchi et al., 2009). Yamaguchi et al. (2013) discov- 
ered that $1 \mathrm{mmol} / \mathrm{dm}^{3}$ of caffeine added to the medium used for thawing cryopreserved wild boar spermatozoa improved pregnancy as well as farrowing rates after artificial insemination, by transiently inhibiting the migration of polymorphonuclear leukocytes into the uterine lumen.

Recently published studies have demonstrated that the supplementation of spermatozoa with 1 up to $10 \mathrm{mmol} / \mathrm{dm}^{3}$ of caffeine significantly decreased the phagocytic and chemotactic activity of polymorphonuclear leucocytes in vitro (Li et al., 2011; Li et al., 2012). Yamaguchi et al. (2009) found an adverse effect on capacitation and spontaneous acrosome reaction of boar spermatozoa when $1 \mathrm{mmol} / \mathrm{dm}^{3}$ of caffeine was present in the thawing medium. Although the addition of high caffeine concentrations during the process of thawing cryopreserved boar semen may increase the number of spermatozoa with a spontaneous acrosome reaction, the fertility rate of sows following artificial insemination may increase.

Methylxanthines, such as caffeine and pentoxifylline, have been shown to increase the motility of spermatozoa in several species including turkeys (Parkhurst et al., 2000), cats (Stachecki et al., 1995), dogs (Koutsarova et al., 1997), rams (Maxwell et al., 1995), and humans (Nassar et al., 1998).

The objective of this research was to study the effects of different concentrations of caffeine on the viability and motility parameters of turkey spermatozoa during in vitro incubation for $5 \mathrm{~h}$ at 5 and $41^{\circ} \mathrm{C}$.

\section{Material and methods}

\section{Animals and semen collection}

In this study, semen from sexually mature turkeys $(n=30)$ of the Big 6line [British United Turkeys (BUT) Ltd., Chester, UK] was evaluated. Semen collection was performed by stimulating the copulatory organ to protrude by massaging the abdomen and the back over the testes. Semen samples were collected with an aspirator and used as a mixture of several groups of identical individual turkeys (Slanina et al., 2012).

\section{Sample preparation}

Fresh turkey semen was diluted in a ratio of 1:100. One part of the fresh semen was diluted in one of 9 caffeine solutions with different concentrations (Caffeine powder, Reagent Plus ${ }^{\circledR}$, Sigma-Aldrich, USA) prepared with physiological saline $(\mathrm{NaCl} 0.9 \%$ w/v intravenous Infusion Bieffe, Bieffe Midetal S.p.A., Grosotto, Italy): I $-0.078125 \mathrm{mg} / \mathrm{mL}, \mathrm{H}-0.15625 \mathrm{mg} / \mathrm{mL}, \mathrm{G}-0.3125 \mathrm{mg} / \mathrm{mL}$, $\mathrm{F}-0.625 \mathrm{mg} / \mathrm{mL}, \mathrm{E}-1.25 \mathrm{mg} / \mathrm{mL}, \mathrm{D}-2.5 \mathrm{mg} / \mathrm{mL}, \mathrm{C}-5 \mathrm{mg} / \mathrm{mL}, \mathrm{B}-7.5 \mathrm{mg} /$ $\mathrm{mL}, \mathrm{A}-10 \mathrm{mg} / \mathrm{mL}$. Two samples of each concentration were prepared and di- 
vided into two experimental groups, based on incubation time at $5{ }^{\circ} \mathrm{C}$ (samples A-I) and in a $41{ }^{\circ} \mathrm{C}$ (thermostat - T: samples AT-IT). Control samples (sample $\mathrm{K} / \mathrm{KT}$ ) were prepared by diluting fresh semen only with physiological solution.

\section{Motility analysis}

The motility of spermatozoa was assessed at six time intervals: $0,1,2,3,4$ and $5 \mathrm{~h}$ (times $0-5$ ). The experiment was carried out in six repetitions. Each of the prepared samples was evaluated using a CASA system - Sperm Vision ${ }^{\circledR}$ program (Minitüb, Tiefenbach, Germany) equipped with a microscope (Olympus BX 51, Japan) to assess the motility of spermatozoa (Massanyi et al., 2008; Kročková et al., 2012; Slanina et al., 2015a).

Each sample was placed into a Makler Counting Chamber ${ }^{\circledR}$ (depth $10 \mu \mathrm{m}$, Sefi Medical Instruments, Germany). Using the turkey-specific set-up, the total motile spermatozoa (MOT, \%) and progressively motile spermatozoa (PRO, \%), beat cross frequency $(\mathrm{BCF}, \mathrm{Hz})$, curvilinear velocity $(\mathrm{VCL}, \mu \mathrm{m} / \mathrm{s})$ and the amplitude of lateral head displacement (ALH, $\mu \mathrm{m})$ were evaluated. Within each measurement by the CASA system motility parameters from minimum seven fields of Makler Counting Chamber were evaluated (Błaszczyk et al., 2013; Slanina et al., 2015b).

\section{Viability analysis}

The viability of spermatozoa was evaluated using eosin-nigrosin staining (Slanina et al., 2016). Membrane integrity was determined in the samples containing the highest concentration of caffeine - in samples A/AT, B/BT, C/CT, $\mathrm{D} / \mathrm{DT}, \mathrm{E} / \mathrm{ET}$ and in the control sample, K/KT. Three smears were prepared from all samples (after the assessment of sperm motility). Experimental samples A-I and the control sample were diluted in a ratio of 1:2:2 with $5 \%$ eosin (Eosin Y, Sigma-Aldrich, USA) and 10\% nigrosin (Nigrosin, Sigma-Aldrich, USA) solution. On every slide, 300 cells were counted under a light microscope $(1000 \times$, Leica DMIL LED, Leica Microsystems CMS GmbH, Germany) and classified as vital (intact membrane) and dead (damaged membrane). The experiment was performed in six replicates. The results of viability evaluation were expressed as the percentage of vital and dead spermatozoa (in \%; 900 cells $=100 \%$ ).

\section{Statistical analysis}

The obtained data were statistically analysed using the PC program Excel and the statistics package GraphPad Prism 5 (GraphPad Software, Inc., La Jolla, California, USA) using one-way ANOVA with Dunnett's test. Statistical significance was indicated by $\mathrm{P}$ values of less than $0.05,0.01$ and 0.001 . 

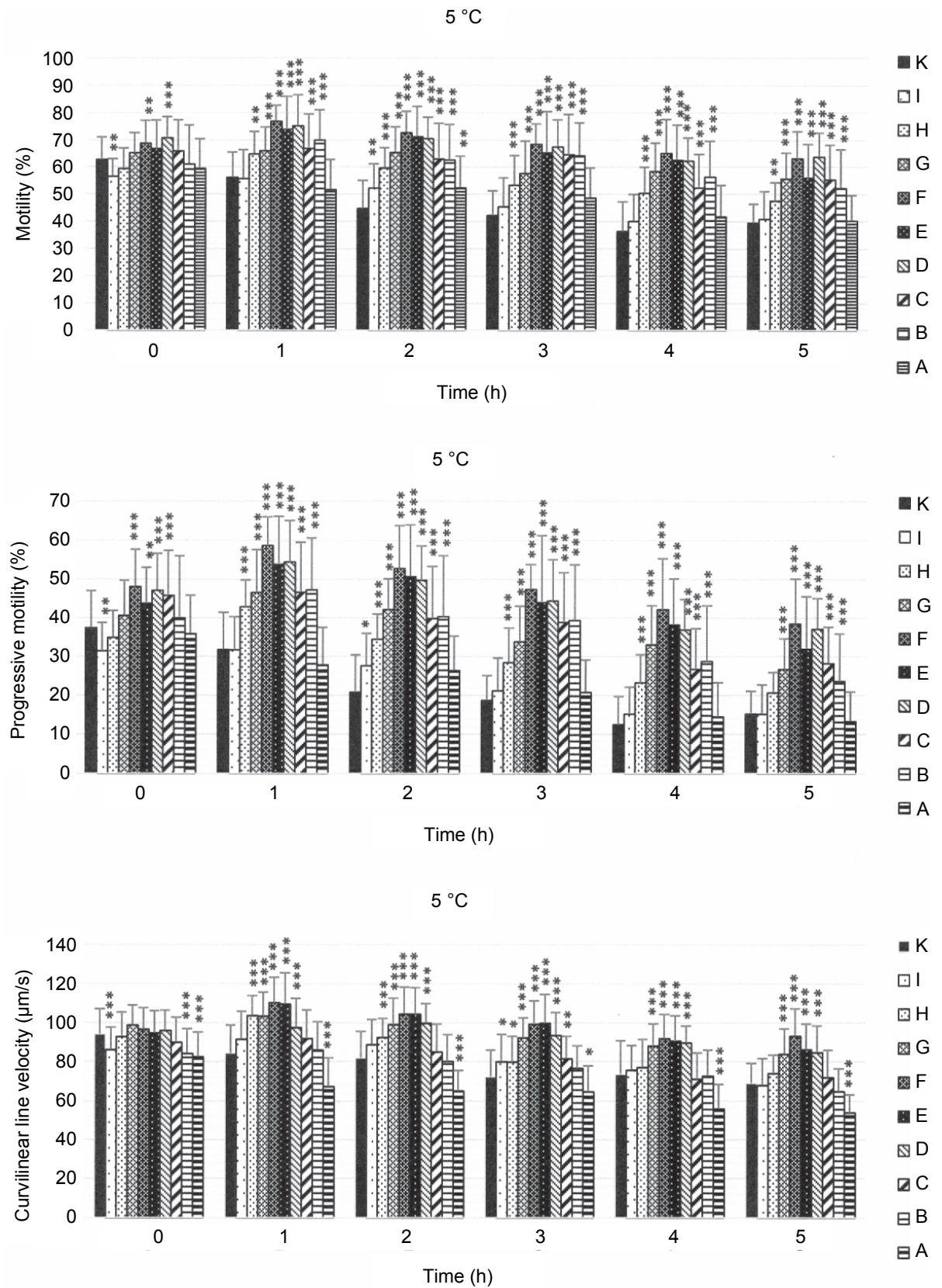

Fig. 1. Motility (\%, mean values), progressive motility ( $\%$, mean values) and curvilinear velocity of spermatozoa ( $\mu \mathrm{m} / \mathrm{s}$, mean values) in groups with various caffeine concentrations at different time intervals (h) at $5{ }^{\circ} \mathrm{C} . \mathrm{K}$ - control; I $-0.078125 \mathrm{mg} / \mathrm{mL}, \mathrm{H}-0.15625 \mathrm{mg} / \mathrm{mL}$,

$\mathrm{G}-0.3125 \mathrm{mg} / \mathrm{mL}, \mathrm{F}-0.625 \mathrm{mg} / \mathrm{mL}, \mathrm{E}-1.25 \mathrm{mg} / \mathrm{mL}, \mathrm{D}-2.5 \mathrm{mg} / \mathrm{mL}, \mathrm{C}-5 \mathrm{mg} / \mathrm{mL}$, $\mathrm{B}-7.5 \mathrm{mg} / \mathrm{mL}, \mathrm{A}-10 \mathrm{mg} / \mathrm{mL}$. Error bars represent the standard deviation. Significant differences: ${ }^{*} \mathrm{P}<0.05 ;{ }^{* *} \mathrm{P}<0.01 ;{ }^{* * *} \mathrm{P}<0.001$ 

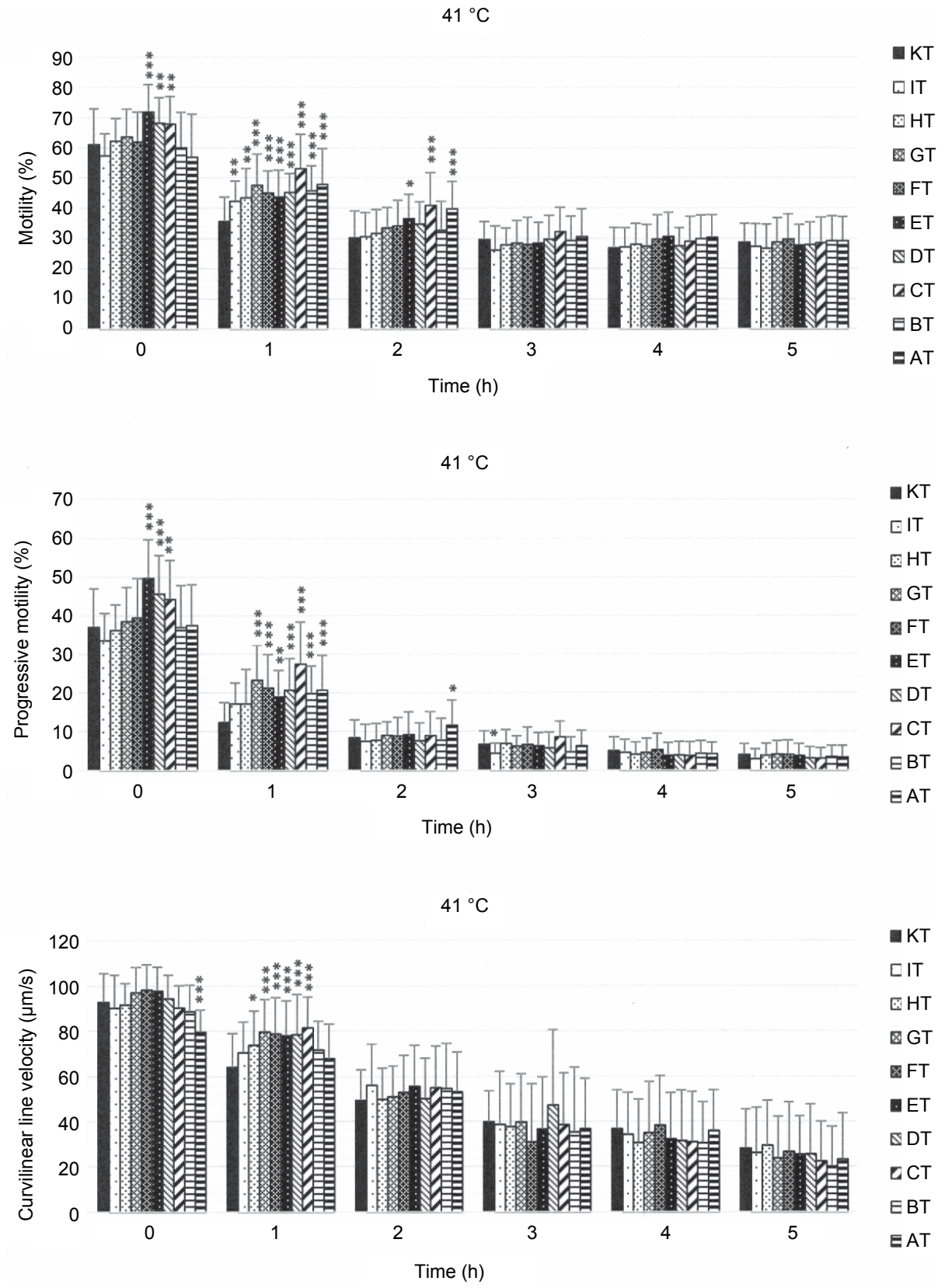

Fig. 2. Motility (\%, mean values), progressive motility ( $\%$, mean values) and curvilinear velocity $(\mu \mathrm{m} / \mathrm{s}$, mean values) of spermatozoa in groups with various caffeine concentrations at different time intervals (h) at $41{ }^{\circ} \mathrm{C}$. KT - control; IT $-0.078125 \mathrm{mg} / \mathrm{mL}, \mathrm{HT}-0.15625 \mathrm{mg} / \mathrm{mL}$, GT $-0.3125 \mathrm{mg} / \mathrm{mL}$, FT $-0.625 \mathrm{mg} / \mathrm{mL}$, ET $-1.25 \mathrm{mg} / \mathrm{mL}$, DT $-2.5 \mathrm{mg} / \mathrm{mL}$, CT $-5 \mathrm{mg} / \mathrm{ml}$, BT $-7.5 \mathrm{mg} / \mathrm{mL}, \mathrm{AT}-10 \mathrm{mg} / \mathrm{mL}$. Error bars represent the standard deviation. Significant differences: ${ }^{*} \mathrm{P}<0.05 ;{ }^{* *} \mathrm{P}<0.01 ;{ }^{* * *} \mathrm{P}<0.001$ 


\section{Results}

\section{Sperm motility at $5{ }^{\circ} \mathrm{C}$ incubation temperature}

By observing the effect of caffeine on selected motility parameters of turkey spermatozoa, several caffeine concentrations having a significantly positive impact on the monitored parameters were determined. At the beginning of incubation motility differences between the control sample and the experimental samples were negligible (Fig. 1). Higher motility was recorded only in samples $\mathrm{D}$ and F. In contrast, a lower motility rate was observed in sample I than in the control. A significant positive effect had been expressed in the first hour of incubation and this phenomenon continued until the end of the incubation period $(5 \mathrm{~h})$. In these time intervals, significantly higher $(\mathrm{P}<0.001)$ percentages of motile spermatozoa were found in samples H, G, F, E, D, C and B. Sample A, supplemented with the highest caffeine concentration $(10 \mathrm{mg} / \mathrm{mL})$, showed a motility conforming to the values recorded in the control in all time intervals.

Progressive motility of turkey spermatozoa confirmed the results of MOT and in several cases differences between control and experimental samples were enhanced (Fig. 1). In the initial time interval, only sample I had significantly lower progressive motility than the control sample. In samples C, D and E, significantly higher values of progressive motility were detected already at the beginning of incubation. The increase of progressively motile spermatozoa was significant in samples B, C, D, E, F and G, and a similar tendency was detected in all the other time intervals. After 1, 2 and $3 \mathrm{~h}$ of incubation, samples D, E and $\mathrm{F}$ not only showed increased progressive motility compared to the control but even exceeded the initial values recorded at time 0 .

A significant negative effect of caffeine on curvilinear velocity (VCL) of spermatozoa was demonstrated in sample A (treated with the highest caffeine concentration) throughout the incubation (Fig. 1). A significant decrease in VCL was noted also in samples B and I but only at the beginning of incubation. In contrast, the addition of caffeine in samples D, E, F and G resulted in significantly higher $(\mathrm{P}<0.001)$ values of this parameter.

An undesirable effect of the highest caffeine concentration (sample A) was detected in the amplitude of lateral head displacement (ALH) and beat cross frequency (BCF) of spermatozoa. The other samples had equal or significantly enhanced values compared to the control sample with regard to these two parameters.

\section{Sperm motility at $41^{\circ} \mathrm{C}$ incubation temperature}

The effect of various concentrations of caffeine during in vitro incubation at $41{ }^{\circ} \mathrm{C}$ was identical with that observed during the first two time intervals of incubation at $5{ }^{\circ} \mathrm{C}$. Compared to the control samples, the experimental samples showed similar or higher values of the sperm parameters studied. However, these 
values did not exceed the values measured in the initial interval. One-hour incubation at $41{ }^{\circ} \mathrm{C}$ resulted in a marked decline in sperm motility and progressive motility in all experimental samples, when compared to the initial values. This decrease was even more pronounced after another hour of in vitro incubation.

Significantly higher sperm motility (Fig. 2) was observed in samples CT, DT and ET at the beginning of incubation. In the subsequent time interval $(1 \mathrm{~h})$, caffeine positively stimulated the spermatozoa $(\mathrm{P}<0.01, \mathrm{P}<0.001)$, which showed higher motility in all experimental samples than in the control sample. After 120 min of incubation, statistically significant differences were observed in groups ET $(\mathrm{P}<0.05), \mathrm{CT}$ and AT $(\mathrm{P}<0.001)$, while no significant difference appeared after 3,4 and $5 \mathrm{~h}$ of incubation.

Significantly higher progressive motility (Fig. 2) was noticed at the beginning of incubation in experimental samples CT, DT and ET, which corresponds to the results obtained on the motility of spermatozoa. Cultivating spermatozoa at $41^{\circ} \mathrm{C}$ for $60 \mathrm{~min}$ resulted in significantly higher progressive motility in samples AT, BT, CT, DT, ET and FT. In the subsequent time interval of in vitro incubation, all samples showed a similar level of motility differing from the control $(\mathrm{P}<0.05)$.

At the beginning of incubation at $41^{\circ} \mathrm{C}$, curvilinear velocity (VCL, Fig. 2) was significantly lower $(\mathrm{P}<0.001)$ only in sample AT $(10 \mathrm{mg} / \mathrm{mL})$ than in the control sample. After one hour of incubation, caffeine demonstrated its positive effect. Significantly higher VCL was observed in samples CT, DT, ET, FT and GT $(\mathrm{P}<0.001)$ and in sample HT $(\mathrm{P}<0.05)$.

By monitoring the effect of caffeine on the amplitude of lateral head displacement (ALH), significant differences were detected only at the beginning of in vitro incubation. Compared to the control, a significantly higher value of this parameter was observed in sample ET $(\mathrm{P}<0.05)$, while a significant negative difference was recorded in sample AT $(\mathrm{P}<0.001)$. The highest concentration of caffeine (sample AT) had a negative effect on beat cross frequency (BCF) in the same time interval. After one hour of incubation, a positive effect of caffeine on ALH was demonstrated. The same incubation time resulted in a significantly increased $\mathrm{BCF}$ when compared to the control sample.

\section{Viability of spermatozoa}

Assessment of the membrane integrity of turkey spermatozoa during in vitro incubation using eosin-nigrosin staining showed that the tested concentrations of caffeine had no significant effect on the viability of the incubated spermatozoa. In the samples containing the highest concentrations of caffeine (samples from A to E) no significant differences were detected (Table 1) compared to the control sample $(\mathrm{K})$. With the increasing time of incubation, a higher percentage of dead spermatozoa was observed at the incubation temperature of $41{ }^{\circ} \mathrm{C}$ than at $5{ }^{\circ} \mathrm{C}$. Independently of the non-significant impact of caffeine on the via- 


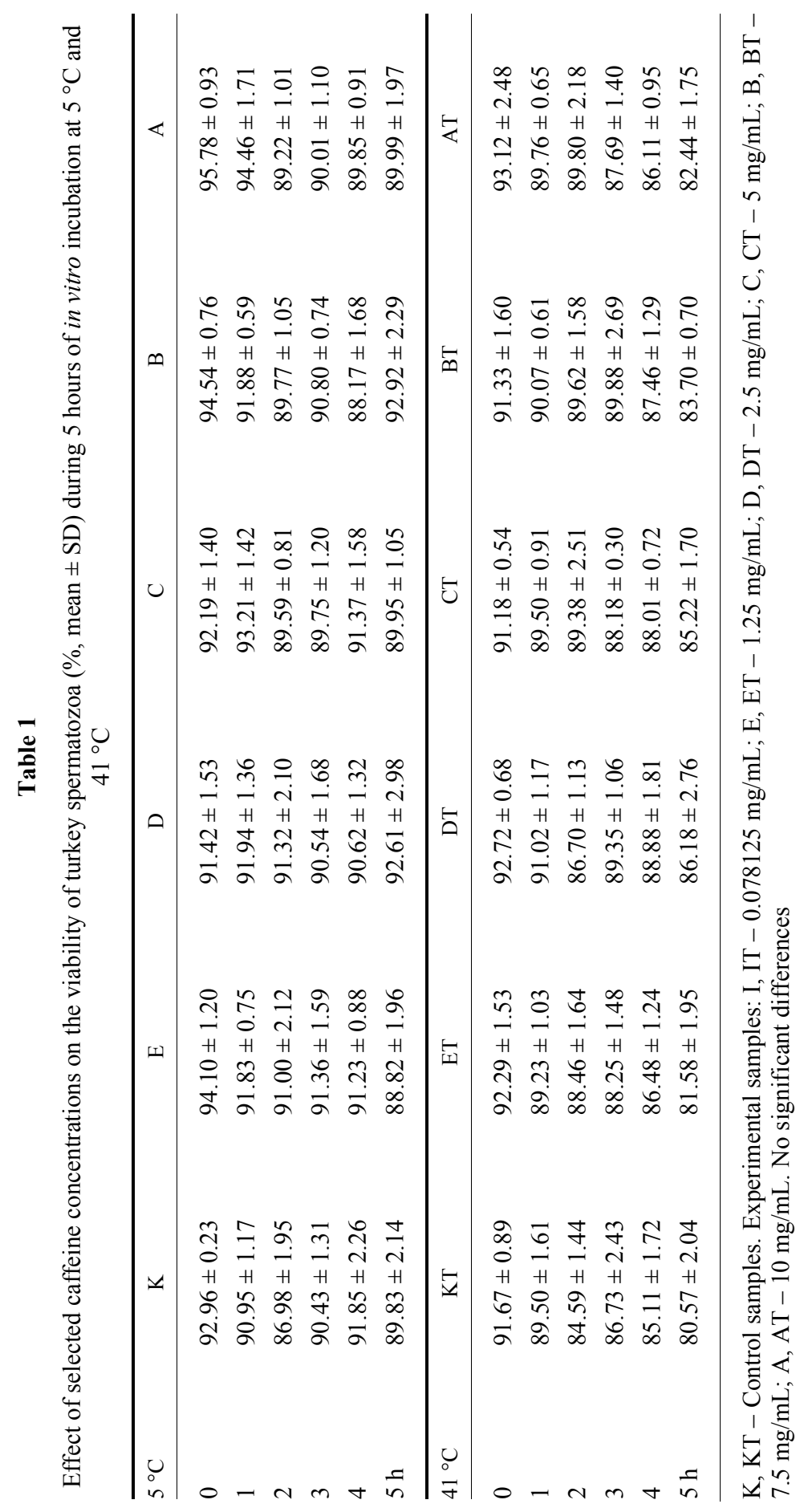


bility of turkey spermatozoa, the results confirmed the negative effect of higher incubation temperature on sperm viability. During the 5-h in vitro incubation higher percentages of spermatozoa with damaged membrane integrity were detected at $41{ }^{\circ} \mathrm{C}$. At that temperature, the percentage of dead spermatozoa was $5.96-11.1 \%$, while at $5{ }^{\circ} \mathrm{C}$ incubation temperature it was only $2.24-5.79 \%$.

\section{Discussion}

Based on previous research on avian and mammalian spermatozoa it is hypothesised that the male gametes of turkey regulate their motility via cAMP as the secondary messenger of the system. In mammals, due to the action of methylxanthine, it is possible to change this regulative system in order to improve the motility of spermatozoa.

Parkhurst et al. (2000) monitored the effects of pentoxifylline and caffeine on the motility of turkey spermatozoa. The selected additives added to the commercial medium BPSE (Beltsville poultry semen extender) at concentrations of $0,2.5,5$ and $10 \mathrm{mmol} / 1$ were found to have an impact after incubation at $5{ }^{\circ} \mathrm{C}$ for $6 \mathrm{~h}$. The results lead to the conclusion that the addition of caffeine during the process of turkey semen storage has no stimulating effect on the motility of spermatozoa. Similar concentrations of caffeine were tested in our study (sample I: $0.625 \mathrm{mmol} / \mathrm{L}$; F: $5 \mathrm{mmol} / \mathrm{L}$; E: $10 \mathrm{mmol} / \mathrm{L}$ ). However, tendencies similar to those reported by Parkhurst et al. (2000) were found only in our sample I.

The present analysis demonstrated a statistically significant $(\mathrm{P}<0.001)$ positive impact of higher caffeine concentrations (samples $\mathrm{E}$ and $\mathrm{F}$ ) on the motility of turkey spermatozoa, which differs from the findings of Parkhurst et al. (2000). This dissimilarity may be explained by the difference in the method used to assess semen motility. While the results of our study were obtained using the CASA system, Parkhurst et al. (2000) used the sperm mobility test (SMT), a test described by Froman and McLean (1996) and Donoghue et al. (1998), which is based on the spectrophotometric determination of absorbance at a wavelength of $550 \mathrm{~nm}$.

The effect of caffeine on particular qualitative sperm parameters has been studied primarily in mammals where many positive effects, associated with the enhancement of intracellular cAMP, have already been proved.

As it was previously mentioned by Yamaguchi et al. (2013), the addition of caffeine to the thawing solution (Modena ${ }^{\mathrm{TM}}$ ) elevates the progressive motility of boar spermatozoa without affecting the membrane integrity of the sperm head under in vitro conditions. A caffeine-enriched boar semen extender may improve fertility by reducing the chemotactic and phagocytotic effect of porcine polymorphonuclear leukocytes (PMN) on sperm cells, which are intended for artificial insemination ( $\mathrm{Li}$ et al., 2012). Gilts inseminated with a caffeine-containing 
sperm suspension had a significantly lower number of uterine PMN than those inseminated with a caffeine-free sperm suspension. The decrease in the number of uterine PMN associated with caffeine may be a consequence of the inhibition of IL-8 mRNA expression in the endometrium.

Yeste et al. (2008) claimed that caffeine exerts a significant stimulating effect on the capacitation and acrosome reaction of boar spermatozoa. Their study suggests that caffeine concentrations varying from 0.5 to $8 \mathrm{mmol} / \mathrm{L}$ significantly $(\mathrm{P}<0.01)$ increase the ratio of capacitated boar spermatozoa as well as the number of spermatozoa with an acrosome reaction. In contrast, lower concentrations of hyaluronic acid do not affect the capacitation process; however, higher concentrations $(200 \mu \mathrm{g} / \mathrm{mL})$ have a significant inducing effect on the acrosome reaction in spermatozoa. Three days of storage of caffeine-treated semen resulted in a significantly elevated frequency of capacitated spermatozoa as compared to the negative control. Furthermore, on the third day the ratio of spermatozoa showing an acrosome reaction was significantly $(\mathrm{P}<0.01)$ higher in samples containing caffeine.

The effect of caffeine has already been demonstrated on thawed equine spermatozoa. Using the CASA method, Taylor et al. (2013) observed a nonsignificant increase in overall and progressive motility after the administration of caffeine at concentrations of 1,2 and $3.5 \mathrm{mmol} / \mathrm{L}$. A significant stimulatory effect on these parameters was found after the addition of pentoxifylline. Considering our results, we suppose that the concentrations tested in the study of Taylor et al. (2013) were inadequate. Higher caffeine concentrations may have a positive effect, and therefore individual sperm motility may be stimulated.

The positive impact of caffeine on individual qualitative parameters of spermatozoa has also been demonstrated in laboratory mice (Nabavi et al., 2013). The addition of caffeine significantly increased the motility and viability of spermatozoa. Besides these parameters, caffeine also increased fertility and the early development of embryos under in vitro conditions.

The effect of caffeine on bovine spermatozoa was studied by Barakat et al. (2015) with the aim to analyse the effect of caffeine, kallikrein and pentoxifylline on the motility of spermatozoa as well as to determine their optimal concentrations which would increase sperm motility after thawing. Sperm cell motility was assessed by the CASA system, which showed that motility and progressive motility was higher in samples containing caffeine and pentoxifylline than in the control samples. The results also indicated that kallikrein had no significant stimulatory effect on the motility of bovine spermatozoa. The best results were obtained after the addition of $5 \mathrm{mmol} / \mathrm{L}$ of caffeine to the medium, followed by the addition of 1 and $5 \mathrm{mmol} / \mathrm{L}$ of pentoxifylline, respectively. It was also demonstrated that lower concentrations of caffeine had a more favourable effect on the motility of spermatozoa than higher levels, which was also confirmed by our results. Therefore, it is recommended to add $5 \mathrm{mmol} / \mathrm{L}$ of caffeine to incuba- 
tion media used for fertilisation. The results of Barakat et al. (2015) are consistent with our findings, as in our study the highest motility and progressive motility were observed in samples F $(5 \mathrm{mmol} / \mathrm{L}), \mathrm{E}(10 \mathrm{mmol} / \mathrm{L})$ and $\mathrm{D}(20 \mathrm{mmol} / \mathrm{L})$.

In conclusion, our analysis of the impact of caffeine on selected parameters of turkey spermatozoa has determined the range of caffeine concentrations (from $0.15625 \mathrm{mg} / \mathrm{mL}$ to $7.5 \mathrm{mg} / \mathrm{mL}$ ) that has a significant stimulatory effect on the motility of spermatozoa $(\mathrm{P}<0.01, \mathrm{P}<0.001)$ without exerting a negative effect on viability parameters during in vitro incubation at $5{ }^{\circ} \mathrm{C}$. The positive effect of caffeine on motility parameters was observed also at the beginning and after 1 $\mathrm{h}$ of incubation at $41^{\circ} \mathrm{C}$.

\section{Acknowledgements}

This work was supported by the Slovak University of Agriculture in Nitra, the Ministry of Education, Science, Research and Sport of the Slovak Republic, and the Slovak Research and Development Agency grant no. KEGA 006/SPU-4/2015, APVV-160289 and APVV-15-0544.

\section{References}

Barakat, I. A., Danfour, M. A., Galewan, F. A. and Dkhil, M. A. (2015): Effect of various concentrations of caffeine, pentoxifylline, and kallikrein on hyperactivation of frozen bovine semen. Biomed. Res. Int. 2015, 1-7.

Barkay, J., Bartoov, B., Ben-Ezra, S., Langsam, J., Feldman, E., Gordon, S. and Zuckerman, H. (1984): The influence of in vitro caffeine treatment on human sperm morphology and fertilizing capacity. Fertil. Steril. 41, 913-918.

Błaszczyk, M., Slanina, T., Massanyi, P. and Stawarz, R. (2013): Semen quality assessment of New Zealand white rabbit bucks. JMBFS 1, 2168-2179.

Carrell, D. T. and Peterson, C. M. (2010): Reproductive Endocrinology and Infertility: Integrating Modern Clinical and Laboratory Practice. Springer, New York, $826 \mathrm{pp}$.

Coscioni, A. C., Reichenbach, H. D., Schwartz, J., Lafalci, V. S. N., Rodrigues, J. L. and Brandelli, A. (2001): Sperm function and production of bovine embryos in vitro after swim-up with different calcium and caffeine concentration. Anim. Reprod. Sci. 61, 59-67.

Donoghue, A. M., Holsberger, D. R., Evenson, D. P. and Froman, D. P. (1998): Semen donor selection by in vitro sperm mobility increases fertility and semen storage in the turkey hen. J. Androl. 19, 295-301.

Froman, D. P. and McLean, D. J. (1996): Objective measurement of sperm motility based upon sperm penetration of Accudenz ${ }^{\circledR}$. Poult. Sci. 75, 776-784.

Funahashi, H. and Nagai, T. (2001): Regulation of in vitro penetration of frozen-thawed boar spermatozoa by caffeine and adenosine. Mol. Reprod. Dev. 58, 424-431.

Harrison, R. F., Sheppard, B. L. and Kaliszer, M. (1980): Observations on motility, ultrastructure and elemental composition of human spermatozoa incubated with caffeine. Andrologia 12, 434-443.

Henkel, R. R. and Schill, W. B. (2003): Sperm preparation for ART. Reprod. Biol. Endocrinol. 1, 108. Koutsarova, N., Todorov, P. and Koutsarov, G. (1997): Effect of pentoxifylline on motility and longevity of fresh and thawed dog spermatozoa. J. Reprod. Fertil. Suppl. 51, 117-121. 
Kročková, J., Massanyi, P., Toman, R., Danko, J. and Roychoudhurry, S. (2012): In vivo and in vitro effect of bendiocarb on rabbit testicular structure and spermatozoa motility. J. Environ. Sci. Health. A Tox. Hazard. Subst. Environ. Eng. 47, 1301-1311.

Li, J. C., Yamaguchi, S. and Funahashi, H. (2012): Boar seminal plasma or hen's egg yolk decrease the in-vitro chemotactic and phagocytotic activities of neutrophils when co-incubated with boar or bull sperm. Theriogenology 77, 73-80.

Li, J. C., Yamaguchi, S., Kondo, Y. and Funahashi, H. (2011): Caffeine, dibutyryl cyclic-AMP and heparin affect the chemotactic and phagocytotic activities of neutrophils for boar sperm in vitro. Theriogenology 75, 1336-1345.

Mao, J., Wu, G. M., Prather, R. S., Smith, M. F., Cantley, T., Rieke, A., Didion, B. A. and Day, B. N. (2005): Effect of methyl- $\beta$-cyclodextrin treatment of pig spermatozoa on in vitro fertilization and embryo development in the absence or presence of caffeine. Theriogenology 64 , 1913-1927.

Massanyi, P., Weis, J., Lukac, N., Trandzik, J. and Bystricka, J. (2008): Cadmium, zinc, copper, sodium and potassium concentrations in rooster and turkey semen and their correlation. J. Environ. Sci. Health. A Tox. Hazard. Subst. Environ. Eng. 43, 563-565.

Maxwell, W. M., Robinson, S. J., Roca, J., Molinia, F. C., Sanchez-Partida, L. G. and Evans, G. (1995): Motility, acrosome integrity and fertility of frozen ram spermatozoa treated with caffeine, pentoxifylline, cAMP, 2-deoxyadenosine and kallikrein. Reprod. Fertil. Dev. 7, 1081-1087.

Nabavi, N., Todehdehghan, F. and Shiravi, A. (2013): Effect of caffeine on motility and vitality of sperm and in vitro fertilization of outbreed mouse in T6 and M16 media. Iran J. Reprod. Med. 11, 741-746.

Nassar, A., Mahony, M., Blackmore, P., Morshedi, M., Ozgur, K. and Oehringer, S. (1998): Increase of intracellular calcium is not a cause of pentoxifylline-induced hyperactivated motility or acrosome reaction in human sperm. Fertil. Steril. 69, 748-754.

Nassar, A., Morshedi, M., Mahony, M., Srisombut, C., Lin, M. H. and Oehninger, S. (1999): Pentoxifylline stimulates various sperm motion parameters and cervical mucus penetrability in patients with asthenozoospermia. Andrologia 31, 9-15.

Paluch, J., Slanina, T., Massányi, P. and Stawarz, R. (2013): The effect of in vitro semen storage temperature and age of males on spermatozoa motility parameters of turkey semen. JMBFS 2, 1642-1649.

Parkhurst, A. M., Korn, N. and Thurston, R. J. (2000): The effects of methylxanthines on the mobility of stored turkey sperm. Poult. Sci. 79, 1803-1809.

Paul, M., Sumpter, J. P. and Lindsay, K. S. (1995): Action of pentoxifylline directly on semen. Hum. Reprod. 10, 354-359.

Slanina, T., Kováčová, R., Lukáč, N. and Massányi, P. (2016): Impact of tilmicosin on the rabbit spermatozoa motility and viability. JMBFS 5, 53-56.

Slanina, T., Miškeje, M., Knížat, L., Mirda, J. and Massányi, P. (2012): The effect of different concentration of trehalose on turkey spermatozoa motility in vitro. JMBFS 4, 573-582.

Slanina, T., Miškeje, M., Petrovičová, I., Lukáč, N. and Massányi, P. (2015a): Changes in turkey spermatozoa motility parameters after addition of copper sulphate in vitro. JMBFS 4, 98-100.

Slanina, T., Petrovičová, L., Miškeje, M., Kňížat, L., Mirda, J., Lukáč, N., Trandžík, J., Petrovičová, I. and Massányi, P. (2015b): The effect of diluent, temperature and age on turkey spermatozoa motility in vitro. J. Appl. Anim. Res. 43, 131-136.

Stachecki, J. J., Presser, B. L., Pope, C. E. and Armant, D. R. (1995): Stimulation of ejaculated domestic cat sperm motility with caffeine, pentoxifylline, and 2-deoxyadenosine. Arch. Androl. 34, 63-68.

Taylor, D. S., Brooks, R. M., Carrington, J. L., Cheng, L., Carrington, A. C., Porr, Ch. A. and Splan, R. K. (2013): Effects of pentoxifylline, caffeine, and taurine on post-thaw motility and longevity of equine frozen semen. J. Eq. Vet. Sci. 33, 615-621. 
Yamaguchi, S., Funahashi, H. and Murakami, T. (2009): Improved fertility in gilts and sows after artificial insemination of frozen-thawed boar semen by supplementation of semen extender with caffeine and $\mathrm{CaCl}_{2}$. J. Reprod. Dev. 55, 645-649.

Yamaguchi, S., Suzuki, C., Noguchi, M., Kasa, S., Mori, M., Isozaki, Y., Ueda, S., Funahashi, H., Kikuchi, K., Nagai, T. and Yoshioka, K. (2013): Effects of caffeine on sperm characteristics after thawing and inflammatory response in the uterus after artificial insemination with frozen-thawed boar semen. Theriogenology 79, 87-93.

Yeste, M., Briz, M., Pinart, E., Sancho, S., Garcia-Gil, N., Badia, E., Bassols, J., Pruneda, A., Bussalleu, E., Casas, I. and Bonet, S. (2008): Hyaluronic acid delays boar sperm capacitation after 3 days of storage at $15^{\circ} \mathrm{C}$. Anim. Reprod. Sci. 109, 236-250.

Yovich, J. M., Edirisinghe, W. R., Cummins, J. M. and Yovich, J. L. (1990): Influence of pentoxifylline in severe male factor infertility. Fertil. Steril. 53, 715-722. 